\title{
Concepts of Causation in Historiography ${ }^{1}$
}

\section{Anton Froeyman}

Centre for Logic and Philosophy of Science

Blandijnberg 2, B-9000 Gent, Belgium

Anton.Froeyman@ugent.be

\begin{abstract}
This paper aims to apply contemporary theories of causation to historiography. The main purpose is to show that historians can use the concept of causation in a variety of ways, each of which is associated with different historiographical claims and different kinds of argumentation. Through this application, it will also become clear, contrary to what is often stated, that historical narratives are (in a specific way) causal, and that micro-history can be seen as a response to a very specific (causal) problem of Braudelian macro-history.
\end{abstract}

\footnotetext{
${ }^{1}$ I would like to thank Erik Weber, Bert Leuridan, Isabelle Drouet, Federica Russo, Rafal Urbaniak, Lindsey Vandevoorde, Jasper Bauters and two anonymous referees for their contributions to this paper. The research leading to this paper was made possible by the FWO Flanders by means of research project nr. 4.0158.05.
} 


\section{1) Introduction}

In an article in Rethinking History from 2005, Frank Ankersmit complained that many debates in the philosophy of history are obscured by the fact that contemporary philosophers of history have, generally spoken, no real command of the technical details of central concepts in contemporary philosophy of science and philosophy of language. (Ankersmit 2005) This is not only the case with philosophers of history, but also (even a fortiori) for practicing historians. It is true that we cannot reasonably expect practicing historians to become philosophers of science and language. Still, there are many concepts, theories and insights to be found which could benefit historians in their research just as well as they could benefit philosophers of history. I believe that this is particularly the case with respect to the concept of causation.

It is often taken for granted (and certainly not just by historians) that causation is a clear concept which can be easily defined or intuitively grasped in a univocal way. This is a mistake. Many metaphysicians and philosophers of science have struggled for several decades now to find a clear and univocal definition or description of what causation is and what it means to say that something causes something else, and I believe it is fair to say that none of them has succeeded in doing so. It might even be plausible to say that none of them has even come close. Because of this, philosophers have in recent years developed a new approach, namely causal pluralism. (see Hall 2004, Cartwright 2007, De Vreese 2006, Hitchcock 2003) Causal pluralists argue that causation as a concept cannot be defined univocally. According to causal pluralism, the monistic theories that have been developed over the years all stress different aspects of causation, but none of them can fully capture the concept. The research program of causal pluralism consists of determining which aspects are caught by which theory, and which of these aspects are used in which context. The aim of this paper is to do so with respect to historiography. I will suggest that different "kinds" of causation are used in different kinds of historical research, and, maybe even more importantly, that historians also use different concepts with regard to one single historical question. By identifying these different types of causation, it will be possible to shed new light on some discussions in the philosophy of history, such as those on the distinctions between the use of narratives and causal statements, and between micro and macro-history. 
In the first part of this paper, I will present the most important theories on causation as they currently stand in Anglo-Saxon philosophy of science and metaphysics. The theories are represented in the text itself only insofar as they will be relevant to applications within historiography. More elaborate remarks are limited to footnotes. I understand that this might not be the most interesting part for historians to read, but I would encourage to do so anyway, because the first part is essential for the correct understanding of the second. In this second part, I will show how these can illuminate historiography by applying them to a number of examples. Because the number of examples is limited, I cannot claim to make any definite statements about the use of the different concepts of causation in history. To do so would require a much more extensive and systematic study. The current paper is meant to be the starting point of such an enquiry rather than its fulfillment. Nevertheless, there is one thing that should become very clear: both historians and philosophers of history cannot take the concept of causation for granted.

\section{2) Theories of causation}

\subsection{Counterfactual and Regularity theories of Causation}

\subsubsection{Hume's legacy}

Counterfactual and regularity theories try to characterize causation in terms of properties of causes and effects, rather than focus on the process or relation which links causes and effects. What happens in between a cause and its effect is regarded as a black box. In this sense, one might say that these theories are actually more about causes and effects than on causation as such. The starting point of any such theory is David Hume, who defines causes in the following ways:

We may define a CAUSE to be 'an object precedent and contiguous to another, and where all the objects resembling the former are plac'd in like relations of precedency and contiguity to those objects that resemble the latter. (Hume 2006a, 114)

Suitably to this experience, therefore, we may define a cause to be an object, followed by another, and where all the objects similar to the first are followed by objects similar to the second. Or in other words where, if the first object had not been, the second never had existed. (Hume 2006b, 60) 
Actually, the second quote consists of two different theories or definitions. In the first quote and the first part of the second quote, Hume defines causation as constant conjunction (every A is followed by B) combined with temporal priority and (in the first quote, but not in the second) contiguity. Therefore, a cause of a certain phenomenon is a cause because it is always followed by its effect. ${ }^{2}$ In the second part of the second quote, he defines causation as counterfactual dependence: A is said to cause B if and only if the following statement is true: "if A had not occurred, B would not have occurred as well".

These two definitions have lead to two different philosophical traditions. On the one hand, some philosophers have focused on the definition of constant conjunction. It became clear almost immediately that demanding a constant conjunction in the strict sense would be too strict. For example, if the rain is the cause of the fact that I get wet, this does not imply that I get wet every single time it rains (I might have an umbrella, or stay inside). The alternative solution seems to be to regard causation as probability raising: despite the fact that I might not get wet every time it rains, I am much more likely to get wet when it does. More specifically, there are much more situations where I get wet and it rains than there are situations in which I get wet and it doesn't rain. Rain can therefore be regarded as a probability raiser for getting wet and, provided there are no common causes for the fact that it rains and the fact that I get wet, therefore also as a cause. Classical formulations of these definitions can be found, among others, in (Suppes 1970) and (Pearl 2000).

On the other hand, some philosophers have elaborated Hume's counterfactual statement, the most influential of which is (Lewis 1983-1986), which developed a counterfactual theory based on possible worlds. Contrary to the tradition based on Hume's first definition, the second one can still be grasped more or less in its essence by referring to Hume's definition, which is why I do not develop this point any further.

\subsubsection{Mutiple causes}

\footnotetext{
${ }^{2}$ In the first quote, but not in the first part of the second, Hume also mentions contiquity as a condition for causation. For reasons of clarity, I will leave this matter aside, since contiguity is, in my opinion, not a real issue in historical causation, contrary to physics for example.
} 
One of the most central problems in the philosophy of causation, and probably the most important one for historiography, is the problem of multiple causes, which was first thematized by John Stuart Mill.

"It is seldom, if ever, between a consequent and a single antecedent, that this invariable sequence
subsists. It is usually between a consequent and the sum of several antecedents; the occurrence of all
of them being requisite to produce, that is, to be certain of being followed by, the consequent. (Mill 1973, 327)".

Despite that fact that we normally select one specific antecedent as the cause, Mill insists that we should call the complete set of antecedents the cause:

In such cases it is very common to single out one only of the antecedents under de denomination of Cause, calling the others merely Conditions. (Mill 1973, 327).

The real Cause, is the whole of these antecedents; and we have philosophically speaking, no right to give the name of cause to one of them, exclusively of the others (Mill 1973, 328).

In Mill's view, singling out one of the antecedents as the cause (and thus distinguishing the cause from mere conditions) may be useful in everyday life, but we should not do this in philosophy, nor in scientific investigation. ${ }^{3}$ Suppose, for example, that a forest is hit by a lightning flash which causes a forest fire. From a scientific point of view, the lightning flash is not in itself the cause of the fire, but only as a part of a complex condition, which might also include the fact that the grass was dehydrated and that there was no fire truck in the vicinity.

I have referred to this point as "the problem of multiple causation", because, despite Mill, it is indeed experienced as a problem in science as well as in common language. Although scientific research is in general more open to multiple causes (or a single cause consisting of multiple parts) than common language, there are limits. Following our example, we could indeed consider both the lightning flash and the dehydration of the grass as additional causes.

\footnotetext{
${ }^{3}$ Mill's theory has been elaborated by John Mackie (Mackie 1974) According to Mackie, A is a cause of B in the ordinary sense of the word if and only if A and B both occur, A is temporally prior to B and A is a so-called INUS condition of B. By the term "INUS condition", Mackie means an Insufficient but Non-redundant part of a Condition, which is itself Unnecessary but exclusively Sufficient for B in the circumstances. The specific complex condition which is said to have caused our forest fire does not need to be a necessary one. It is perfectly possible that the forest might have caught fire without a lightning flash (for example if someone had dropped a match). The different INUS conditions of the forest fire can be seen as possible causes in the ordinary sense of the word, as opposed to the full cause, which is a disjunction of complex conditions (both positive and negative). Just as Mill, Mackie only considers this full cause to be the genuine cause. INUS conditions can only be said to be causes in a practical sense in common speech, not in philosophy or science. (for a more detailed summary of Mackie's theory and some specific applications, see Horsten \& Weber 2005).
} 
But do we also have to consider the presence of oxygen on earth (which is a precondition for trees to grow) or the Big Bang itself as causes or parts of a cause? In a philosophical discourse this might be defendable, but in actual scientific research this seems absurd. It seems to be the case that, even if we do consider multiple causation, we still make some kind of selection, based on what is relevant for a given situation. Although this selection might be less arbitrary and more encompassing in scientific than in common language, the need for such a selection still exists.

Herbert Hart and Tony Honoré were the first to develop an explicit criterion for a selection of this kind. They state, more or less, that our identification of causes depends on contextual factors, in the sense that only phenomena which are considered to be at odds with the normal course of events can be considered to be causes. (Hart \& Honoré 1985, 33) According to Hart \& Honoré, the condition we select as cause is regarded as such because it stands out with respect to a certain "default status of the world". Most of this "default status" is common to most people within a certain context. The fact that there was a Big Bang, for example, is presupposed in almost all cases, except in some causal statements in astrophysics. Nevertheless, some factors of this default status of the world can vary significantly in different circumstances. Hart \& Honoré give two examples in which they illustrate this.

In most cases where a fire has broken out the lawyer, the historian and the plain main would refuse to say that the cause of the fire was the presence of oxygen, though no fire would have occurred without it: they would reserve the title of cause for something of the order of a short-circuit, the dropping of a lighted cigarette, or lightning. Yet there are contexts where it would be natural to say that the presence of the oxygen was the cause of the fire. We have only to consider a factory where delicate manufacturing processes are carried on, requiring the exclusion of oxygen, to make it perfectly sensible to identify as the cause of a fire the presence of oxygen introduced by someone's mistake. (Hart \& Honoré 1985, 11)

The cause of a great famine in India may be identified by the Indian peasant as the drought, but the World Food Authority may identify the Indian government's failure to build up reserves as the cause and the drought as a mere condition. (Hart \& Honoré 1985, 35 \& 1966, 219)

Depending on whether one is an Indian farmer or a member of the World Food Authority, the cause of the famine is different. Either we regard the drought as normal, which makes the failure to stockpile food the cause, or either we consider the failure to stockpile food as normal, in which case the drought is the cause. (see also Menzies 2007, 209-211) This does not mean that one is right and the other wrong. Both statements are right with respect to the 
perspective of the one who states it. This does not make causal statements non-objective or arbitrary in any way, since the perspective itself, or the situation out of which it arises, is perfectly describable in an objective way. ${ }^{4}$

Hart \& Honoré regard this process of selection as a negative procedure: only what is not regarded as normal can be selected as a cause. Recently some philosophers have formulated it in a positive way. They state that the conditions we select out of a background are typically conditions which we are (or could be) able to change or manipulate. (see especially Woodward $2003^{5}$ ) According to this approach, the value of a variable A causes the value of variable $\mathrm{B}$ if an intervention on the value of $\mathrm{A}$ would also entail (or would have entailed) a change in the value of B. For example, heat causes a thermometer to rise, because if we would lower the heat, the thermometer would drop as well. By contrast, if we raise the mercury level in the thermometer, the environment does not get any warmer or colder. It is not important whether these interventions are practically possible. Causal interventionists and manipulationists typically define causation in terms of possible interventions. They state that we speak of relations as causal only when we imagine that we could intervene or could have intervened (as is the case in historiography).

Defining causation is one thing, offering methods for finding causes and effects in specific cases is something else. The basic methods for the identification of causes according to the theories mentioned above have been formulated by John Stuart Mill in his two canons of induction. It is important to note that, according to Mill, only the second one (the Method of Difference) is capable of providing reliable knowledge on causes and effects.

\footnotetext{
${ }^{4}$ Partly because of the problem of the selection of causes, in which such a completely neutral and objective point of view often seems impossible, it has been recently suggested that causation should be considered to be a "perspectivalist" concept. (see Menzies 2007, Price 2007) Briefly said, the idea is that causation is a concept which we, as human agents, use to make sense of an underlying world describable by non- (or less-) perspectivedependant notions such as counterfactual dependence, or alternatively, laws of nature. Although causal perspectivalism in itself as a philosophical position has nothing to do with the selection of causes, it is quite clear that the notion of causation as a perspective-dependent concept is prompted by the problems which arise from the selection of causes.

${ }^{5}$ It should be noted that, strictly speaking, Woodward does not refer to manipulations, but a technical notion of an "intervention", which is believed to be definable without reference even to possible or thinkable manipulations by us as human agents. Since, however, we are not doing metaphysics here, and Woodward's account clearly starts from manipulations as a root metaphor or basic intuition of what the essence of causation consists of, I believe it is at this point better to start from manipulations and interventions as understood by commons sense as basic. I believe this does not make a difference with regard to applications to historiographical examples. For a more detailed picture of Woodward's theory of causation, the reader is referred to (Woodward 2003).
} 

"If two or more instances of the phenomenon under investigation have only one circumstance in
common, the circumstance in which alone all the instances agree, is the cause (or effect) of the given
phenomenon." (Mill 1973, 390)

"If an instance in which the phenomenon under investigation occurs, and an instance in which it does not occur, have every circumstance in common save one, that one occurring only in the former; the circumstance in which alone the two instances differ, is the effect, or the cause, or an indispensable part of the cause, of the phenomenon." ( Mill 1973, 391)

Mill's method of difference forms the starting point of the modern experimental methods that are used to discover causes in most of the social sciences and large parts of the medical sciences. (see Horsten \& Weber 2005 for some examples)

\subsection{Process theories \& Mechanisms}

The second kind of theories try to describe causation not by referring to properties of causes and effects, but by focusing on the process of causation itself, which runs from an effect to a cause. The two most important groups of theories are the process theories by Wesley Salmon and Phil Dowe (Salmon 1984 \& 1998, Dowe 2000), and the theories about mechanisms by Stuart Glenann (1996), Peter Machamer, Lindley Darden \& Carl Craver (2000).

\subsubsection{Causal Processes}

The general idea of a theory of causation as a process has been around in philosophy of science for quite a while (in the accounts of, among others, Russell, Reichenbach, Skyrms, Aronson and Fair), but became especially influential through Wesley Salmon's formulation in 1984. The basic concept of Salmon's theory is the notion of a causal process. The concept of a causal process can be intuitively grasped as the movement of a persistent object through time and space ${ }^{6}$, such as a rolling billiard ball or a space station flying in orbit around the earth. The idea is that this process is causal because the fact that the flying space station is at a

\footnotetext{
${ }^{6}$ Note, however, that in Salmon's theory, the notion of 'process' is not defined in terms of objects, but is taken as a primitive term (see Hitchcock 1995 306). In Dowe's theory, however, processes are indeed defined in terms of objects. (Dowe 2000, 90) Again, since we are not concerned with the metaphysics of causation at this point and because I believe that the concept of a causal processes is intuitively easier to understand in terms of objects, I will use it in this way. For deeper understanding, the reader is referred to the discussions in the fourth and fifth chapter of (Dowe 2000).
} 
certain point at a certain time is caused by the fact that it was at a slightly different point at a slightly earlier time. This fact again is caused by the fact that it was at a slightly different point at a slightly earlier time, and so on. This is the case again and again for every point of time and space in the trajectory of the space station. The concept of causation is therefore present throughout the whole process, which is why it is called a causal process. ${ }^{7}$ It is not possible to single out specific causes and effects, because all there is, is an infinite number of positions in time and space which cause, and are caused by, each other. Therefore, a causal process cannot be described by a limited number of specific causal statements of the form " $\mathrm{A}$ causes B".

Apart from causal processes on their own, Salmon also talks about interactions between causal processes. The idea of a causal interaction is based on the root metaphor of two colliding objects such as billiard balls. Basically, a causal interaction occurs when there is an intersection of two causal processes (e.g. when two billiard balls collide) which results in a change in the properties of both causal processes, for example speed and direction. ${ }^{8} \mathrm{~A}$

\footnotetext{
${ }^{7}$ Salmon makes a distinction between causal processes (such as a billiard ball running on a flat surface) and pseudo-processes (such as a spot of light which moves across a wall) by introducing the idea of mark transmittance. Intuitively, this criterion is introduced to ensure that the object involved in the process is a "real" object. A process can only be a causal process when it could be (or could have been) capable of transmitting a so-called mark, a certain (minor) change in the properties of the object which forms the basis of this causal process. If this cannot or could not be done, the object in question cannot be the basis of a causal process. In a pseudo-process such as the movement of a spot of light on a wall, making such a mark is impossible. A typical example of marking is making a cut in a baseball before throwing it. Salmon defines the idea in the following way:
}

Let be a process that, in the absence of interactions with other processes, would remain uniform with respect to characteristic $\mathrm{Q}$, which it would manifest consistently over an interval that includes both of the space-time points $\mathrm{A}$ and $\mathrm{B}(\mathrm{A} \neq \mathrm{B})$. Then a mark (consisting of a modification of $\mathrm{Q}$ into $\mathrm{Q}$ '), which has been introduced into process by means of a single local interaction at point $\mathrm{A}$, is transmitted to point B if manifests the modification Q' at B and at all stages of the process between A and B without additional interventions. (Salmon 1984, 148)

\footnotetext{
${ }^{8}$ Salmon defines a causal interaction in the following way:
}

Let $\mathrm{P} 1$ and $\mathrm{P} 2$ be two processes that intersect with one another at the space-time point $\mathrm{S}$, which belongs to the histories of both. Let $\mathrm{Q}$ be a characteristic that process P1 would exhibit throughout an interval (which includes subintervals on both sides of S in the history of P1) if the intersection with P2 did not occur; let R be a characteristic that process $\mathrm{P} 2$ would exhibit throughout an interval (which includes subintervals on both sides of S in the history of P2) if the intersection with P1 did not occur. Then, the intersection of $\mathrm{P} 1$ and $\mathrm{P} 2$ at $\mathrm{S}$ constitutes a causal interaction if:

(1) P1 exhibits the characteristic Q before S, but it exhibits a modified characteristic Q' throughout an interval immediately following $\mathrm{S}$; and

(2) P2 exhibits $\mathrm{R}$ before $\mathrm{S}$ but it exhibits a modified characteristic $\mathrm{R}$ ' throughout an interval immediately following S. (Salmon 1984, 171). 
collision between two billiard balls is a causal interaction because the speed and direction of both balls are significantly altered after the collision. An intersection of two spots that are projected on a wall by spot lights is not a causal interaction, since the spots can move through each other without their speed, direction or any other important characteristic being altered.

Although Salmon and Dowe's theories were developed in the first place as theories of causation in the physical world (the world as described by physics), it has been suggested that, if interpreted in somewhat more functional and analogical terms, their theories can give us important insights in the social sciences as well. (Weber 2007) We will see that this is very much the case for historiography.

\subsubsection{Mechanisms}

A more recent attempt to define the process of causation itself is undertaken by the different theories about mechanisms, the most important of which are those of Stuart Glennan and Peter Machamer, Lindley Darden and Carl Craver. Intuitively, the basic idea of these approaches is that a mechanism is a chain of events which runs from a cause to an effect. A cause is a cause and an effect is an effect because they are linked by a mechanism. The events which form the parts of the chain are generally thought to consist of certain types of entities (for example individuals, organs, molecules,...,) which have certain types of influences on each other. For example, the fact that I toggle a light switch is a cause of the fact that the light goes on, because by pushing the light switch, I remove a barrier for an electric current, which ends up in a thin filament inside a light bulb, which consequently heats up and produces light. Therefore, one can say that there is a mechanism which runs from the event of me toggling a light switch to the event of the light bulb lighting up. A second example is taken from Dan Steel, who in turn adopted it from Bronislaw Malinowski.

Phil Dowe has taken over the idea of a causal process and a causal interaction from Wesley Salmon, but he has also suggested some changes. The most important of these changes is the replacement of the mark transmittance criterion by a different criterion: that of a conserved quantity. A process is a causal process, according to Dowe, when the object involved in it possesses a certain kind of conserved quantity, most typically a physical quantity such as momentum or energy. Next to this, Dowe defines a causal interaction not as an intersection which involves a change in properties, but which involves an exchange of a conserved quantity. Wesley Salmon largely agreed with Dowe, and abandoned his original position. (Salmon 1994) 
For example, consider the anthropologist Bronislaw Malinowski's (1935) account of how having more wives was a cause of increased wealth among Trobriand chiefs. Among the Trobrianders, men were required to make substantial annual contributions of yams to the households of their married sisters. Hence, the more wives a man had, the more yams he would receive. Yams, meanwhile, were the primary form of wealth in Trobriand society and served to finance such chiefly endeavors as canoe building and warfare. Although individuals play a prominent role in this account, they do so as representatives of social categories: brothers-in-law, wives, and chiefs.

Mechanisms come in two slightly different kinds, which can be labeled "complex-system mechanisms" and "mediating mechanisms". (Weber \& Leuridan 2008) The first example is a mediating mechanism, the second a complex-system mechanism. The difference between complex-system mechanisms and mediating mechanisms can best be explained in terms of levels. In a complex-system mechanisms, cause and effect are situated at different levels, for example between the individual and the population level, or they are at the same level, but the mechanism which links them "runs" at a different level. Complex-system mechanisms are especially present in biology, where the behaviour of a certain organ is often explained by referring to the parts of which it consists as the cause of this behaviour. (see, Glennan 1996, Machamer, Darden \& Craver 2000) Steel's example is a complex-system mechanism, because the relation between cause and effect - the number of wives a man has and his wealth - is set at the aggregate (or population) level. The mechanism, however, is given in terms of the (determinate) behaviour of individuals. In a mediating mechanism, on the other hand, cause and effect as located at the same level and are connected by a mechanism which "runs" at this very same level. A mechanism in this sense can run, for example, from an action by one individual to another individual, or from one variable to another. (see Pearl 2000, Morgan \& Winship 2007). ${ }^{10}$

\subsection{Preliminaries in applying concepts of causation}

\footnotetext{
${ }^{9}$ Note that the authors to which I refer do not use these terms themselves, but just talk about "mechanisms" as such.

${ }^{10}$ The description of mechanisms given above is largely similar to that of Peter Hedström and Richard Swedberg (1998), but there is an important nuance. According to Hedström and Swedberg, a mechanism should always be, at least in an limited sense, general. A simple description of a chain of events which leads from one event to another will not do. This is not the case, at least not in principle, in most parts of the philosophical literature. In the following parts of this paper, I will use the concept(s) of mechanism as it is defined in the philosophical literature, regarding simple descriptions of chains of events as examples of mechanisms.
} 
As we have said, I will use these theories in a pluralistic way. This means that I am convinced that none of these theories presents a complete account or theory of what causation is in itself or how it should be understood, but that all of them point at specific ways common people and scientists use to find causes and effects and to interpret causal relationships. In the following part, I will show that this approach fits very well within historiography. In the first place, it should become clear that historians do indeed use different concepts or intuitions about causation in different kinds of research, and, more importantly, different concepts of causation within the same historical study. Second, by applying these criteria, two important points will present themselves. First, contrary to what is often stated, the macro-history of the second generation of the Annales is (partly) narrative instead of causal. Second, micro-history appears to be essentially causal instead of narrative.

\section{3) Causation in Historiography}

\subsection{What, How and Why}

Historiography consists of giving answers to three different types of questions: what-, howand why-questions. (Stanford 1998, 128-129, Stone 1979, 5) The first group is concerned with what we make of events in the past. They consider the question whether a certain predicate is applicable to a certain historical event, person or situation. Historians have wondered, for example, whether or not the French Revolution was a radical break with the ancient régime, or whether François Rabelais could or could not be considered to have been an atheist. This type of enquiry, however, does not (at least not directly) involve any kind of causal statements, so I will not treat it any further here.

The two other types of enquiries, the how- and what-questions, do require "causal" statements as their answers. I put the term "causal" between inverted commas, because there is an essential difference in how causation and causal statements are used in the answers to both kind of question. The answer to a why-question is typically a causal statement. If we ask "why did something happen?" or "why does a certain event, situation or person have a specific property?", we expect the answer to begin with "because...". It is possible in principle to summarize any historiographical work which presents such an argument in one sentence of the form "A was caused by B". Henri Pirenne's Mahomet et Charlemagne, for 
example, can (disrespectfully) be summarized into the statement "The rise of (the specific nature of) Medieval Europe as we know it was caused by the closing off of the Mediterranean by the Arab world". We cannot give such a one-sentence summary of historical narratives, which form answers to historiographical how-questions, such as "how did the French revolution develop", or "how did the price of wheat in the ancient régime evolve?" Nevertheless the concept of causation also plays a part in the construction of narratives, as we will see shortly.

\subsection{What are historical narratives?}

A narrative is sometimes mistaken for a simple description of a series of events. Despite the fact that every narrative is certainly descriptive, it is also something more. A narrative describes its facts in a coherent way, with a certain direction and meaning. Morton White has given the following example: the sentence "The King of England died, which led the Queen to grieve, which led the princess to worry." could be an example of a (historical) narrative, while the sentence "The King of England died, and then the queen grieved, after which the princess began to worry." could not. (Dray 1971, 162) In the second sentence, the events are simply put alongside each other, while in the first one, there is a causal relation between the different events, through which they are combined to form a coherent whole.

Furthermore, in order to be a narrative, a text should also have a clear and meaningful ending and beginning. If not, it is not a narrative, but what Hayden White and Michael Stanford call a "chronicle". (White 1987, 16-19, Stanford 1998, 219) One of the main arguments for the difference is that the ending or the further course of a narrative can have a definite influence on the characterization of every part of it. $\mathrm{H}$. White gives the following example.

The king went to Westminster on June 3, 1321. There the fateful meeting occurred between the king and the man who was ultimately to challenge him for his throne, though at the time the two men appeared to be destined to become the best of friends. (White 1973, 5)

So a historical narrative is not just a coherent (causal) ordering of a number of events. The narrative itself, as a whole, also influences the nature of the parts of which it consists. 
Next to these two features (causal coherence and a definite ending/beginning), a narrative should have two other properties, which are strongly interrelated with each other. First, every narrative should have a plot (it should be, for example, a tragedy, a comedy, a satire,...), which Hayden White defines as "a structure of relationships by which the events contained in the account are endowed with a meaning by being identified as parts of an integrated whole". (White 1973,9 ) Because it has a plot, a narrative constitutes a story, and because every story is a story about something, a narrative should also have a central subject. (Dray 1971, 157) Such a subject does not necessarily have to be physically stable over time. Ranke's History of the popes is a narrative about a purely institutional and conceptual entity ("the pope"), not about a physical thing. (Ranke 1847) Augustin Thierry's essay “Histoire Véritable de Jacques Bonhomme" (Thierry 1835) has as its central subject an ideal-type form of the French Farmer, whose experiences take many centuries, and who leads a purely conceptual existence. (Ginzburg 1991, 85-86) It is therefore up to the historian to define his research subject in a way he or she believes is suitable for (narrative) historical enquiry.

To summarize, I have summed up four interrelated criteria which a text should fulfill in order to be a narrative:

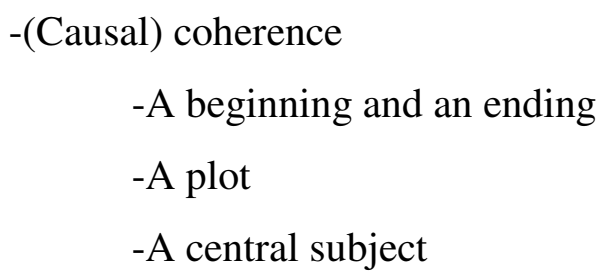

These traits are structural, they do not refer in any way to the content of narratives. If we are in search of general statements about, for example, the scientific validity of narratives or the use of causation, this is the kind of definition we need. Scientific validity cannot be decided on the basis of what it is that is being researched, but only on how it is researched, which is a structural notion. The same goes for causation. Whether the statement "A causes B" is true or false cannot be decided on the basis of what kind of things A and B are, but only on the basis of the relation between the two, which is, again, a structural notion. In none of the theories of causation we have discussed above, substantial statements about what A and B are made, only general (structural) statements such as "event", "object", "complex", "entity”,...

It is important to mention this, because a large part of the critique which is often given on the use of narratives in historiography is aimed mainly at specific substantial traits, which cannot 
be part of a general critique on the validity of the use of narratives. Fernand Braudel, for example, claimed that narratives were always about particular individuals, most often kings or heroes, who were masters of their own fate and whose lives were dominated by dramatic coincidental events, (Braudel, quoted in White 1987, 32) whereas his own historiographical approach was concerned with the common man, whose life was dominated by all sorts of impersonal overarching structures. This critique is not justified, because even fictional narratives are certainly not necessarily concerned with free heroes who live by their own rules, and this is a fortiori true for historical narratives. It is perfectly possible for a historical narrative to be about the common man and the impersonal structures by which his life is determined (for example Augustin Thierry's essay, cf. infra), or even to be not about individual people but about institutions, nations, practices etc. It might be true that, generally spoken, narratives have the tendency to focus on individuals, but this is not necessarily the case and does not in principle form an argument against the use of narratives in historiography.

A second objection Braudel and a lot of other historians hold against narratives, is that a historian who uses historical narratives as a mode of explanation is thought to give a true and indubitable account of history wie es eigentlich gewesen ist. This again is not a necessary consequence of the use of narratives. The combination between narratives and the "positivist"11 historiography is a consequence of the coexistence of both concepts in Germany in the first half of the nineteenth century. The use of narratives was the dominant way of writing history in a period during which historians still believed that a decisive, monotonic and objectively true historiography was possible. However, the fact that most modern champions of the narratives, such as Paul Ricoeur, Hayden White and Frank Ankersmit, are among the fiercest opponents of this objectivist ideal, shows that narratives and historiographical positivism do not necessarily have a connection.

As an illustration, I will give a very short example of what can be seen as a typical historical narrative, namely the Staatsrecht-hypothesis which was formulated by Wilhelm Arnold in 1854. (Arnold 1854) Arnold presented a theory about the origins and development of the typical medieval city as a continuous development from the early medieval domain.

\footnotetext{
${ }^{11}$ One should watch out for a confusing use of the term "positivism". In philosophy, "positivism" refers most of the time to the logical positivism of the Wiener Kreis, which has very little to do with the positivism which is often ascribed to Ranke. I want to make it clear that in this paper, "positivism" refers to the Rankean ideal, not to that of the Wiener Kreis.
} 
According to Arnold, urban development started off in the eight century with a domain which was ruled by the bishop ${ }^{12}$ and populated by two groups of people, one non-free and one free. The first of these groups is subjected to the jurisdiction of the bishop, the second one only to that of the state. As time went by, both groups became intermingled and the difference between the two became quite vague. After a while, there was a conflict between church and state, and the bishop wanted to gain jurisdiction over the whole population. This population, which had become quite free at this time, refused to be subjected again, took the side of the state (the emperor, the count,...) and rebelled. Out of this rebellion, the first urban communal institutions arose. (Pirenne 1939, 5-7)

This is clearly a (historical) narrative. It has a central subject ("the medieval city", or even "the city as such"), a clear beginning (the domain of the early Middle Ages, which is seen as the earliest form of the later medieval city, the germ out of which it grew) and a clear ending (the typical medieval city of the High and Late Middle Ages). It also has a certain kind of plot: the medieval city undergoes a number of characteristic changes which are taken together in a certain way, in this case a kind of progressive development towards the typical medieval city. Also, the different stages of the development are not just put alongside each other in a chronological order, but are clearly interrelated.

\subsection{Causation and Historical Narratives}

As already said, a historical narrative cannot be summarized into a single causal statement of the form "A caused B". In the case of Wilhelm Arnold's thesis, for example, this is impossible. Arnold is not in search of the cause of the existence of the typical Medieval city, but of its origins. This is a consequence of the way he defines and regards his research subject. Because he presupposes a gradual development of a single central subject of enquiry ("the city" in general) which remains present throughout the narrative, he cannot regard this subject as a cause or effect of something else, because this implies the existence of two different central subjects of enquiry (if one speaks of a cause, there is always an equally important effect, and vice versa). In the same way a seedling is not the cause of a tree or a

\footnotetext{
${ }^{12}$ Arnold treats only the episcopal cities, because these are supposed to give the clearest picture of urban development.
} 
caterpillar of a butterfly, the domain in the early Middle Ages is not the cause of the later Medieval city. It is just an earlier stage of the same thing.

Despite the fact that narratives offer no overall causal statements, causation and causal statements are still involved. As we have seen, it is because the different statements of a historical narrative are causally related that the narrative in question is coherent. ${ }^{13}$ Causation plays a central part in one of the four criteria listed above, namely coherence. A series of descriptive statements is coherent because every statement is the effect of the one it immediately follows. A narrative forms what can be described as a "causal chain". (Dray 1971, 162) It is worth noting that the demands for such causal chains are usually more rigorous in historical narratives than in fictional ones. In fiction it is, for example, no problem to make a "jump" of twenty years through time, or to suddenly end up on another continent. In historical narratives on the other, such spatio-temporal jumps are usually not (or less) acceptable.

This notion of a narrative as a causal chain corresponds to the concept of a causal process. As we have already said, a causal process, such as the movement of a space station through space, is also constituted by (an infinite ${ }^{14}$ number of) instances of specific "causation", but does not result in any definite causal statements. In both types, every member of the chain is the effect of the member it immediately follows. It is precisely because of this causal link that narratives are coherent.

Second, both causal processes and narratives need some kind of "central subject" or "object" which remains constant throughout the development of the process. This requires that Salmon and Dowe's notion of causal process is interpreted in a less physical. Salmon and Dowe want to make sure that their theory is about physically "real" entities, and they introduce extra criteria to identify these. In the case of historical narratives, we take the subject of research as defined by the historian (such as "the medieval city", for example) as basic. Because of this, the notion of causal process becomes relative to the framework of the historian: "the medieval city" is a valid entity of enquiry because the historian defines and treats it as such, not because it can be proven to be a physically real entity. This is even more clear with subjects such as "the pope", which do not physically exist. Only specific popes do, not "the pope" as an

\footnotetext{
${ }^{13}$ It might be that there are still other ways than causation to create coherence. In this paper, however, I leave those aside.

${ }^{14}$ Narratives might not literally consist of an infinite number of such "causal" statements, but in every narrative, there are explicit and implicit "causal" statements enough to treat them as analogue to causal processes
} 
institution. One should be aware of interpreting the concept "the pope" or "the papacy" to physically. The fact that a narrative about the pope should stick to its subject, does not mean that it should only include popes, and not, for example, Italian noblemen or The Holy Roman Emperor. The concept "the pope" does not just refer to the physical person who happens to be pope, but also to a network of possible relations this person has to, for example the Holy Roman Emperor, the Vatican, the French King, the Italian cities,... Moreover, this network of relations is precisely what it is that makes specific persons popes. If a history of the popes would only be about the influence of one pope on his successor and so on, it would not really be a history of the papacy, but just a series of narratives about some random people.

Thirdly, causal processes also have something of a plot. The fact that we interpret the trajectory of a spaceship around the earth as an orbit, more specifically an ellipse, has the same characteristics as a plot. It is a structure of the process as a whole, which endows every part of this process with a meaning as a part of this whole. Each specific point of its trajectory gets its meaning only in relation to the general structure of its movement, for example an orbit around a planet. The only difference between (historical) narratives and causal processes seems to be that causal processes do not seem to require a definite ending and a beginning. Because of this, narratives can be considered to form a specific subset of causal processes, provided the term "causal process" is used in a somewhat more analogical way as in the original accounts of Dowe and Salmon.

To conclude this section, it has become clear that there is indeed a strict difference between narratives and historical statements, but that this difference does not simply consists of the absence or presence of causation, but rather of the way causation is used. A historical narrative is made coherent by causal statements, but cannot itself be seen as a causal claim. As we will see in the next section, answers to historiographical why-questions on the other hand can indeed be seen as causal claims.

\subsection{Counterfactuals in historiography: the Pirenne-thesis}

In contrast to Wilhelm Arnold's Staatsrecht-hypothesis, the Pirenne thesis about the origin of Medieval feudal Europe is clearly an answer to a why-question. It was an attempt to explain the rise of Medieval Europe and its transition from the Classical era into the Medieval. Pirenne believed that this transition did not take place in the fifth century, as was generally 
thought, but at the end of the seventh century. He stated that the economical structure of the late Roman Empire continued to exist until the advance of the Arab world, which turned the Mediterranean Sea into a "lac Musulman" (a "Muslim lake"). Pirenne supposed that this event led to the formation of Medieval Europe. As I have already said, Pirenne's thesis can be summarized as a statement of the form "A caused B", namely "The rise of (the specific nature of) Medieval Europe as we know it was caused by the closing off of the Mediterranean Sea by the Arab world". Furthermore, Pirenne uses quite a lot of causal terminology in the formulation of his general thesis. (Weinryb 1975, 36)

We might wonder why there is a need for such a causal thesis in the first place. Why could the transition from Ancient to Medieval society not be described by a historical narrative with the Western Society in general as its central subject, similar to what Arnold does? The reason is this. Pirenne wanted an explanation for the existence of something he regarded to be a essentially new phenomenon: the typical (essentially feudal) character of Medieval Europe. While for Arnold the typical medieval city was not essentially new, but the consequence of a continuous development which started from the classical domain, Pirenne believed there is an essential difference between Medieval and pre-Medieval Europe. The typical character of Medieval Europe was at a certain point created. Because Pirenne's thesis is about this creation, the typical Medieval Europe is not present throughout his story. Because of the fact that it is necessary for a narrative to have a central subject all through the narrative, a causal statement such as Pirenne's cannot be described by a historical narrative as we have described it above. In summary, Pirenne cannot use a historical narrative, because his thesis is a causal one. Pirenne wanted to know the answer to a why-question, which is always a causal statement of the form "A caused B".

Now we can take a look at what Pirenne thought to mean by saying that "the rise of (the specific nature of) Medieval Europe as we know it was caused by the closing off of the Mediterranean Sea by the Arab world." He does this by referring to counterfactual dependence. Pirenne summarized his thesis as follows, which gave its name to the title of his book Mahomet et Charlemagne.

Without Islam, the Frankish Empire would probably never have existed, and Charlemagne, without Mahomet, would be inconceivable. (Pirenne, quoted in Weinryb 1975, 36) 
So the rise of Islam caused the existence of the Frankish Empire, because, if Islam had not risen, the Frankish Empire would not have existed. This clearly implies the basic form of a counterfactual definition of causation, where it is said that A caused B iff if A had not been the case, B would not have.

Nevertheless, there is more to the Pirenne thesis. Pirenne argues for his thesis by describing a link between the rise of Islam and the existence of the typical (feudal) character of medieval Europe. The beginning of this argument is the rise of Islam, the end is the rise of Medieval Europe, and the argument itself consists of a series of mediating factors which link the beginning of this argument to its end. Pirenne states that the Arabs closed the Mediterranean Sea to Christian commerce, which lead to the disappearing of the merchants as a social class. Because of this, the society became almost purely agrarian, which led to the typical feudal structure of the Medieval Society in which all power belonged to the land owners. ${ }^{15}$ This corresponds to the notion of a "mediating mechanism", which we have described above. Pirenne argues for the existing of a link between two variables (the rise of Islam and the existence of Medieval Europe as we know it) by positing additional variables which play a mediating role. In total, there are two quantitative variables, the amount of Western merchants (m) and the amount of long distance trade (t), which is measured by the number of gold coins found on archeological sites, and two qualitative variables, the existence of Western feudal society (f) and the blocking off of the Mediterranean by Moslims (b), which can only take the values 1 or 0 . Pirenne states that there is a causal relationship between $b$ and $t, t$ and $m$, and $m$ and $\mathrm{f}$, and as a consequence also between $\mathrm{b}$ and $\mathrm{f}$.

To summarize, the Pirenne-thesis is a causal statement, because it is answer to a why-question with respect the creation of something essentially new. Pirenne basically interprets this causal relation as counterfactual dependence, but he argues for it by means of a mediating mechanism. This is a first indication that some historians do indeed intuitively use different concepts of causation in their research.

\subsection{Max Weber and the comparative method}

\footnotetext{
${ }^{15}$ The most comprehensive account of the Pirenne-thesis can be found in Mahomet et Charlemagne, translated into English as Mohammed and Charlemagne. Our two-line description is, again, a very disrespectful summary of the argumentation structure of this book.
} 
One possible critique one could give to Pirenne's argumentation is that it is not clear on what grounds the statement that "without Islam, the Frankish Empire would probably never have existed, and Charlemagne, without Mahomet, would be inconceivable" is based. Why could there not have been an alternative cause which would have caused the existence of Medieval Europe if there was no rise of Islam? To be able to give an answer to this type of questions, we need Mill's method of difference.

"If an instance in which the phenomenon under investigation occurs, and an instance in which it does not occur, have every circumstance in common save one, that one occurring only in the former; the circumstance in which alone the two instances differ, is the effect, or the cause, or an indispensable part of the cause, of the phenomenon." (cf. infra)

To be able to apply this method, we need at least two cases. Because there are no two cases of the development of Medieval Europe, Pirenne has to imagine what would have happened without the rise of Islam. This way of thinking is quite common in historiography. When these "what if" histories are explicitly developed, they are called thought-experiments. Robert Fogel, for example, has used this explicitly (contrary to Pirenne and many other historians, who do this implicitly). (Fogel 1964) Fogel wanted to know whether the existence of railroads was the cause of American economic growth, which he investigated by opposing two situations: one real, American economic history as it really happened, with railroads, and one imaginative, which contains exactly the same initial circumstances, except for the existence of railroads.

Of course, depending on imaginative "what-if"-histories in historiography is quite speculative and involves high risks, which is why Pirenne had to back up his counterfactual statement with the help of a detailed mechanism. (for a closer look at thought experiments in historiography, see De Mey \& Weber 2003) Therefore, it is usually better to make comparisons with existing situations. This is what Max Weber has done. Weber's historiographical problem was similar to Pirenne's. Just as Pirenne, Weber wanted to give an explanation for the existence of something new. In Pirenne's case, this was the feudal Medieval society of Western Europe. In Weber's case, it was the existence of our own modernist, rationalist and capitalist society that was in need of an explanation. Because he suspected that the cause of the development of capitalism had something to do with religion, he compared Western society with other comparable societies with different religions or ethics, among others the Roman Empire, Confucianist, Taoist and Buddhist China and Hindu 
India. He came to the conclusion that it must have been the very specific work ethic of Protestantism which was the decisive factor, since this was the only factor that was absent in the non-Western cultures Weber studied and present in the Western.

The method of difference, or the comparative method in general, is widely spread in the social sciences in general, but its use in historiography often involves problems. Because a historian does not generate his own evidence (such as is the case with, for example, statistical sociological or psychological research) but is dependent upon the sources, it is often much more difficult to find a large amount of comparable cases. A related problem concerns the comparability of different historical situations. Partly because of the low amount of comparable cases and partly because of the complicated nature of history and historiography, historical situations often have to be reformulated into very abstract models in order to make them comparable. Because of this high level of abstraction, the application of the historical method has often been seen more as "historical sociology" than as historiography. This necessarily entails a lack of accuracy and detail, and as a consequence, a lack of historical "feeling" for the uniqueness of a historical situation. Nevertheless, comparison is, as we have seen, often crucial as an argument for causal relations.

Because of the problems of the comparative method in historical research, it often cannot be used on its own, but has to be accompanied with back-up evidence in the form of social mechanisms. Like Pirenne, Weber offers a mechanism as an argument for his causal statement that modern society was caused by the protestant ethic. He presents this mechanism in "The Protestant Ethic and the Spirit of Capitalism". (Weber 2002) In normal circumstances, the pursuit of ever-renewing financial profit, which Weber regards as the essential feature of modern capitalism, is not possible, because individuals tend to try to minimize their efforts in seeking gain and avoid work whenever possible. As a consequence, they usually stop making profit when they think they've had enough, or they resort to the irrational pursuit of profit (for example with the use of violence). Only in the protestant ethic, where work was seen as a moral duty, success in business as a benevolent religious sign, but violence on the one hand and pleasure, leisure and luxury on the other hand as sins, could the continuous and rational pursuit for economic gain become commonly accepted. The mechanism Weber posits can best be seen as a complex-system mechanism, because Weber posits patterns of behaviour in 
individuals to account for a property (namely its rationalist and modernist character) of the society as a whole.

As a conclusion to the last two sections, we can say that, in the cases of both Pirenne and Weber, the basic causal claim is interpreted as counterfactual dependence, but this claim is supported by mechanisms. This seems to point out that historians interpret the concept of causation as a plurivocal concept, involving at least two essentially different characterizations. A more systematic study of the historiographical literature would be required to verify this hypothesis.

\subsection{Macro-history, narratives and causation}

The macro-history that originated in the 1950's and which was typical for the second generation of the Annales, the journal Past and Present, the Anglo-Saxon New Economic History and the German Gesellschaftsgeschichte, is often seen as aimed against traditional narrative history and proclaiming a new kind of history-writing, which was supposed to be strictly scientific and causal, instead of merely descriptive. Nevertheless, it will become clear that, if we apply the concepts of narrative and causation developed above to this kind of history, narratives still play an essential part.

The essence of the Braudelian perspective is the introduction of different levels of history. Braudel pretended to have unearthed new layers of history, which did not show up in the traditional sources or using the traditional methods. He distinguished three levels. The first consists of the almost stationary interaction between man and his natural environment, the second of the slowly changing social and economic structures, and the third of the quickly changing political events. (Braudel 1969) In the first volume of Civilization \& Capitalism, he makes a different distinction. Here he distinguishes between three different levels of economic life. The best-known level is that of the traditional market economy. Yet underneath this level, there is a shadowy zone which often does not show up in the sources. Braudel calls this material civilization, and describes it as an infra-economy, the "world of self-sufficiency and barter of goods and services within a very small radius" Above the market level, Braudel characterizes another level, the complex social institutions and "anomalies" which have a decisive influence on the mechanisms of the market. (Braudel 2002, 24) 
The most important feature of Braudelian historiography is (as becomes clear by the fact that Braudel uses two very different distinctions of levels of history) not the specific nature of these different levels, but merely the idea itself that history consists of different levels, that there are always different "histories", or better, different viewpoints on a single historical development. As we will see, it is in relation to this "leveledness" of history that the concept of causation comes in.

Braudel does not posit any why-questions in his work. The Mediterranean and the Mediterranean World in the age of Philip II, for example, cannot be summarized into one statement of the form “A caused B". (Megill 2007, 92-93) In this sense, it is more similar to the narrative history of historians like Ranke and Arnold than to Pirenne or Weber. Does this mean then that Braudel himself actually still wrote the traditional narrative history against which he reacted so strongly? The answer is no, because there is a distinctly new feature in the way Braudel writes history, namely the use of different levels of history. Each of these levels is in itself described with the help of traditional narratives. In a Braudelian history of the bottom-level, for example, we have one specific topic, which could be called "material life". We do not get any statements about its origin, or about certain general historical laws that are active in this domain. Instead, we just follow material life as it develops and changes gradually through time. This is in fact as much a historical narrative as the history of the medieval city or the history of the pope. It has a central topic, namely material life. It also has a beginning and an end, simply the points where the historian chooses to start and end his story. The first volume of Braudel's "Civilization and Capitalism", for example, starts more or less in 1300 and ends around 1800. Furthermore, there is a continuous coherence between the status of material life at a certain moment and that at a later or earlier moment. In fact, the aim (and the great merit) of a historical study in the spirit of Braudel is to provide, as much as the sources allow, an image of such a smooth and continuous development. This is done by showing how different aspects of material life influence each other at different moments, without leaving too much gaps or unexplained developments or evolutions. The development of material life also contains, admittedly in a quite abstract way, a plot: it has peaks and valleys, descents and ascents. It can be cyclical, or it can evolve towards a height (like a traditional romance) or a low point (like a satire).

Despite the fact that a narrative at one specific level can be interesting in itself, it is still vital that these different levels are connected with each other. If this is not the case, there would be 
nothing really new about the Braudelian perspective. It would just consist of a collection of three different, traditional narrative histories, without any reference to how they relate to one another. What is actually given in this way are three different histories, instead of one history with three different aspects. Suppose, for example, we have a historical study on daily life during the Industrial Revolution in England consisting of three parts. The first describes the economic developments, the second the development of the social structure and the third the evolution of culture. If these three narratives are not connected, if, for example, there is no reference to culture or social structure in the economic part or vice versa, there is not one England during the Industrial Revolution, but three different Englands and three different Industrial Revolutions which happen, in some mysterious and unexplained way, to have taken place in the same region during the same period. It is only by making clear that these three chapters are really three perspectives on the same historical situation, that we can say we have a history of daily life during the Industrial Revolution. To be able to do this, we have to articulate an interaction between the different levels. Only in this way a new kind of total and multi-faceted history is possible.

It is in this relation between different levels that the concept of causation comes in. Aspects, structures or historical factors which are present at one level are supposed to have a certain influence on certain aspects, structures or historical factor at different levels. This influence is typically put in causal terms. If we say, for example, that culture reflects the socio-economic structures, this entails that the specific cultural situation at a certain time in history is caused by the socio-economic circumstances, in some kind of counterfactual sense: if the socioeconomic would have been different, i.e., if a specific arrangement of socio-economic circumstances would not have occurred, the cultural situation would be different, i.e. the correlating specific cultural arrangement of circumstances would not have occurred. This is compatible with most of the different counterfactual formulations of causation. If we would have wanted to manipulate the cultural situation, we should have done so by manipulating the socio-economic situation, while the converse is not the case. Also, if we have a number of comparable socio-economic circumstances, we will also expect to have a number of comparable cultural circumstances. ${ }^{16}$

\footnotetext{
${ }^{16}$ Note that this does not imply that there is one-to-one relation between socio-economic and cultural situations. It might just as well be a one-to-many relationship (which is the case in most Marxist or Marxism-inspired theories).
} 
As Allan Megill points out, Braudel never quite succeeded in making a (causal) link between the different levels of history. (Megill 2007, 93) If we keep the framework sketched above in mind, we can see why this is the case. We have seen, in the examples of Pirenne and Weber, that a counterfactual (and by extension also a manipulationist or interventionist) historical statement should be supported be a mechanism. If not, the causal claim which is expressed by the counterfactual is simply too speculative. The only way in which one can avoid mechanisms is by appealing to general laws or models, but these kinds of (usually statistical) laws require extensive and rigorously performed experiments on different groups and controlgroups, or a large amount of data on comparable populations. Such experiments or data are only available to the historian in some very rare cases. Therefore, the Braudelian historian is forced to provide mechanisms.

In some cases, it is very well possible to provide mechanisms between, for example, economic and social and cultural circumstances. For example, one can state that long periods of famine can change the inner structure of the society of a certain village, as a result of which the cultural "codes" for social behaviour might also change. In the case of macro-history, however, there is a problem because of the scale. It is one thing to describe a relation between a famine and a social conflict, but quite another thing to describe the relation between the production of resources over a period of centuries and the world view of the population of, for example, the entire Mediterranean area. A further problem is the direction of the causal influence. Thus far, I have assumed for the sake of the argument that there is a clear direction from the economic level to the social and cultural level. As almost every contemporary historian knows, however, this is too simple. On a small scale, this is not always a problem. It is quite straight-forward, for example, to say that a change in values of a certain population (the result of, for example, a conversion to another religion) causes a change in the way they produce their food. On a large scale, however, one would require a general image about which level influences which other level, in which specific way, and under which circumstances.

The underlying reason for the fact that macro-history has problems with providing mechanisms between different levels, is that of different background conditions. We have already come across the concept of background conditions in the first part of this paper. The general idea was that only those factors which are considered to be variable are able to be considered as causes and effects. On a small scale, there is quite a lot that is considered to form a fixed context. For example the climate, the long-term modes of production, 
technology, gender differences, social hierarchies,... The only things that are considered to be variable are sudden events like failed harvests. Therefore, since there are not that many things to explain, it can be possible to provide a mechanism. On a macro-scale, however, there are many more things (if the scale is large enough, all of the ones mentioned above) which become variable. Therefore, there are many things that need (causal) explaining, and this would entail a very complicated model which comprises the influences of such diverse factors as climate, failed harvests, gender differences, religious beliefs, quarrels between individual actors,... upon each other. Articulating such a large-scale and all-encompassing model in history has, one can fairly say, proven itself to be impossible.

Combining different kinds of models is not an option as well. This might solve the problem of the relation between historical levels, but it would introduce a different and maybe even more problematic distinction between different histories, namely that between histories described by different models. Instead of a economic, social and cultural Industrial Revolution, one would end up with, for example a Marxist, Parsonian or Foucauldian Industrial Revolution, which would entail, mutatis mutandis, the same problems as described above.

To summarize, it is simply not possible to formulate mechanisms at this scale. Nevertheless, as we have seen through the examples of Pirenne and Weber, historiographical causal statements are in need of mechanisms as back-up evidence for counterfactual causal claims, since these counterfactuals cannot be warranted by extensive and reliable experimental research on an array of comparable populations. Because of this, almost every historiographical causal statement needs to be supported by a mechanism. In the case of macro-history, however, such mechanisms are too complex to be found. Therefore, statements about causal relationships between events of different levels (as opposed to different events at the same level, which are situated in a narrative) will always be speculative, and the different levels of macro-history will tend to develop into different histories instead of different aspects of the same history. Therefore, macro-history in the Braudelian sense could not fulfill the task it set itself of presenting a "total history". It is as a reaction to this flaw that micro-history originated.

\subsection{Micro-history and levels of causation}


The micro-history of Ginzburg, Levi, Le Roy Ladurie, Davis, Darnton and others is often thought to have nothing in common with macro-history à la Braudel. I believe this is mistaken, and that micro-history can be seen as a direct response to the problem of linking the historical levels described above. In a micro-historical situation, the levels are a priori linked, precisely because of the small scale. On this scale, it is intuitively (through the use of common sense, one could say) clear what the mechanisms are between, for example, cultural, social and economic levels. It does not require scientific justification to state that, for example, people in a certain village got mad, frustrated or disappointed because of several years of failed harvests. It can almost, as a matter of speech, be read directly from the sources. The merit of (good) micro-history is that it does more than just dwell on this small-scale description. It links the interaction between events on the small scale to structures and general tendencies on a larger scale.

Robert Darnton, for example, starts in The Great Cat Massacre from a typical small scale phenomenon: the (true) tale, told by Nicholas Contat, of a riotous massacre in Paris somewhere in the late 1730's of a large number of cats, which was apparently seen as extremely funny by contemporaries. (Darnton 1984) Because it isn't funny at all in our contemporary eyes (just cruel) Darnton wanted an explanation for the fact that it was thought to be so in the eighteenth century. He did so by referring to more general economical and cultural structures. He first noticed that there was an economic unbalance between employers and employees. The workers were generally mistreated by their patrons, which lead to a sense of frustration of the workers towards their superiors. Then, Darnton gives a further account of different symbolic structures, sexually loaded jokes about cats, the identification of masters with their pets,... In the massacre of cats, all of these contexts came together to form a humorous cocktail. So Darnton links the different levels of history (cultural, economical, social,...) by stating they have a common causal influence on one specific small-scale event, in which the different levels appear as intuitively and a priori interrelated. The interesting thing for us is that this influence is causal and that it occurs between different levels of history: long-term and short-term, and cultural, social and economic. In this sense, microhistory is a continuation of Braudelian macro-history.

In essence, micro-history gives up one part of the scope of macro-history in order to preserve another part, the link between the different levels of history. In one sense, it is a total history, but in another it is not. It is a total history because it describes all aspects of human life 
(social, economical, cultural) in an image of one particular event, and it uses the concept of causation to do this. The disadvantage is that this can only happen from a narrow point of view, namely by starting from one specific short-lived historical event. In other words, the ideal of a decisive and total history with a large scope in time and space, written from an overarching point of view is given up.

The methodology of a historiography which aims at the explanation of single small-scale events ${ }^{17}$ through different (causal) influences from different levels has been formalized by Lawrence Stone and Peter Gay. They both introduce three levels of historical causation. Gay calls these "Long Range Causes", "Short Range Causes" and "Releasers". Stone makes a distinction between "preconditions", which make the event possible, "precipants", which make it probable, and "triggers", which are supposed to make the event necessary. (Lorenz 2002, pp 146-147) If we interpret this in terms of concepts of causation we get a mix of concepts. The preconditions are defined in terms of counterfactuals. Without the preconditions, the event itself would have been impossible. The precipants are defined in terms of (often non-quantifiable) probabilities. They are supposed to make the event a lot more probable, or to seriously raise the chance that it happens. The third kind, triggers, are defined in terms of constant conjunction of an effect with respect to its cause, or more specifically, of sufficient conditions. A is a trigger if, given the circumstances, every time A occurs, it is absolutely necessary that B also occurs. (For an elaboration of the difference between triggers and causes, see Dretske 2004)

To conclude the last two sections, it has become clear that Fernand Braudel still uses historical narratives, despite the critique he himself has given on their use. The innovative aspect of Braudelian historiography consists of the introduction of different levels of history, as a result of which different narratives are placed alongside each other. Because of this, it is necessary to connect these different levels, and this is done by positing causal relations between them. On the macro-scale, however, this seems very difficult or even impossible. Micro-history can be seen as a solution to this problem. In a small-scale event, the different levels of history are linked in an a priori intuitive way. Their relation to processes on a larger scale is made clear by a three-layer scheme which consists of three kinds of causal relations. The disadvantage of micro-history is that these large-scale processes are only seen from the

\footnotetext{
${ }^{17}$ Although this model is most characteristic for micro-history, it is also used for events on a larger scale, for example the English Revolution or the First and Second World War.
} 
point of view of a small-scale event, which implies that part of the universality of the Braudelian perspective is given up.

\section{Summary}

The aim of this paper was to show that historians and philosophers of history should not take the concept of causation for granted. There is an array of often very different theories on causation in philosophy, most of which are also used in historiography. We have seen that, varying with the research problems and the definition of the subject of historiographical enquiry, different concepts of causation are used. Furthermore, these different concepts are often combined. Mechanisms, for example, can be used to give support to causal claims interpreted as counterfactuals, and different concepts of causation are used to connect different levels of history in micro-history. Next to this, is has also become clear that, although there is indeed a strict distinction between historical narratives and causal statements, this does not mean that causation is absent in narratives altogether. Also, since an analogy can be drawn between causal processes, which are mainly based on physics and the exact sciences, and historical narratives, it can be stated that the difference between narrative historiography and practices in other sciences is, although still important, not as radical as is often thought. Next to this, we have also suggested that the macro-history in the Braudelian fashion is still essentially narrative, while micro-history is essentially causal. Seen in this way, micro-history can be seen as a reaction on methodological problems which were present in macro-history. 
-Ankersmit, F. 2005. Reply to professor Saari. Rethinking History 9: 23-33.

-Arnold, W. 1854. Verfassungsgeschichte der Deutschen Freistädte, Gotha, Perthes.

-Braudel, F.1969. Histoires et Sciences Sociales. La Longue Durée, in: Ecrits sur l'Histoire. Braudel, F. 41-84. Paris, Flammarion.

-Braudel, F. 2002. The structures of everyday life, London, Phoenix Press, 2002.

-Cartwright, N. 2007. Hunting causes and using them. Cambridge, Cambridge University Press.

-Darnton, 1984, The great cat massacre and other episodes in French cultural history, New York, Basic Books.

-De Mey, T. \& Weber, E. 2003, Explanation and thought experiment in history, History and Theory 42: 28-38.

-De Vreese, L. 2006. Causal pluralism and scientific knowledge: an underexposed problem. Philosophica 77: 125-150.

-Dretske,F. 2004. Psychological vs. Biological Explanations of Behavior, Behavior and Philosophy 32: 167-177.

-Dowe, P. 2000. Physical causation, Cambridge, Cambridge University Press.

-Dray, W.H. 1971 On the Nature and Role of Narrative in Historiography. History and Theory 10: $153-171$.

-Fogel, R. 1964. Railroads and American Economic Growth, Baltimore, Johns Hopkins University Press.

-Ginzburg, C. 1991. Checking the Evidence: the judge and the historian, Critical Enquiry 18: 79-92.

-Glennan, S. 1996. Mechanisms and the nature of causation. Erkenntnis 44: 49-71.

-Hall, N., Two concepts of causation, Causation and Counterfactuals. ed. J. Collins, N. Hall \& L.A. Paul. 225-276, Cambridge Massachusetts, The MIT Press, 2004. 
-Hart, H. \& Honoré, T. 1966. Causal judgement in history and the law. Philosophical analysis and history. ed. Dray, W. New York, Harper and Rowe.

-Hart, H. \& Honoré, T. 1985. Causation in the law. Oxford, Clarendon Press.

-Hitchcock, C. 2003. Of Humean bondage. British Journal for the philosophy of science. 54: $1-25$.

-Horsten, L. \& Weber, E. INUS conditions. Encyclopedia of statistics in behavioral science, vol 2. Ed. Everett, B. \& Howell, D. 955-958. Chichester, Wiley.

-Hume, D. 2006a [1739-1740]. A treatise on human nature. Oxford, Oxford University Press.

-Hume, D. 2006b [1748]. An Enquiry concerning human understanding. Oxford, Oxford University Press.

-Lewis, D. 1983-1986. Philosophical papers, New York, Oxford University Press.

-Lorenz, C. 2002 De Constructie van het Verleden. Een Inleiding in de Theorie van de Geschiedenis, Amsterdam, Boom. Translated into English as Lorenz, C. 2007, Constructing the past. An introduction to the philosophy of Chris Lorenz, Princeton, Princeton University Press.

-Machamer, P., Darden, L. \& Craver, C. Thinking about mechanisms. Philosophy of Science 67: $1-25$

-Mackie, J. 1974. The cement of the universe: a study of causation. Oxford, Clarendon Press.

-Megill, A. 2007. Historical knowledge, historical error. A contemporary guide to practice, Chicago, University of Chicago Press.

-Menzies, P. 2007. Causation in context. Causation, physics and the constitution of reality. Ed. Price, H. \& Corry, R., Oxford, 250-292. Clarendon Press

-Mill, J.S. 1973 [1843]. A system of logic ratiocinative and inductive: being a connected view of the principles of evidence and the methods of scientific investigation. Ed. Robsson, J.M. Toronto, University of Toronto Press.

-Morgan, S. \& Winship, C. 2007. Counterfactuals and causal inference: methods and principles for social research. Cambridge, Cambridge University Press. 
-Pearl, J. 2000. Causality: models, reasoning and inference. Cambridge, Cambridge University Press.

-Pirenne, H. 1939. L'Origine des Constitutions Urbaines au Moyen Age. Les Villes et les Institutins Urbaines I. Pirenne, H. Paris, Alcan.

-Pirenne, H. 2008. Mohammed and Charlemagne, Mineola, Dover Publications.

-Price, H. 2007. Causal perspectivalism. Causation, physics and the constitution of reality. Ed. Price, H. \& Corry, R., Oxford, 250-292. Clarendon Press.

-Ranke, L. History of the popes, their church and state, s.l., William H. Colyer.

-Salmon, W. 1994. Causality without counterfactuals. Philosophy of Science 61: 297-312.

-Salmon, W. 1984. Scientific explanation and the causal structure of the world. Princeton, Princeton University Press.

-Suppes, P. 1970. A probabilistic theory of causality, Amsterdam, North Holland.

-Stanford, M. 1998. An Introduction to the Philosophy of History. Malden, Blackwell,

-Stone, L. 1979. The Revival of the Narrative, History and Theory 18: 3-24.

-Steel, D. 2004, Social mechanisms and causal inference. Philosophy of the social sciences 34: $55-78$.

- Thierry, A. 1835. Histoire Véritable de Jacques Bonhomme, d'après les Documents Authentiques, Dix Ans d'Etudes Historiques, Thierry, A. 301-311. Bruxelles, Meline, 1835.

-Weber, E. 2007. Conceptual tools for causal analysis in the social sciences. Causality and Probability in the Sciences F. Russo \& J. Williamson, London, King's College.

-Weber, E. \& Leuridan, B. 2008. Counterfactual causality, empirical research and the role of theory in the social sciences. Historical Methods: 197-201.

-Weber, M. 2002. The protestant ethic and the spirit of capitalism. Oxford, Blackwell.

-Weinryb, E. 1975. The Justification of a Causal Thesis. An Analysis of the Controversies over the Theses of Pirenne, Turner and Weber. History and Theory 14: 32-56. 
-White, H. 1973. Metahistory. The Historical Imagination in Nineteenth-Century Europe, Baltimore, Johns Hopkins University Press.

-White, H. 1987. The Content of the Form: Narrative Discourse and Historical Representation, Baltimore, Johns Hopkins University Press.

-Woodward, J. 2003. Making things happen, Oxford, Oxford University Press. 